\title{
RAMAN SPECTRUM OF CRYSTALLINE CADMIUM ACETATE DIHYDRATE
}

\author{
By N. KRIShNamurthy \\ (Department of Physics, Indian Institute of Science, Bangalore-12) \\ Received November 30, 1964 \\ (Communicated by Professor R. S. Krishnan, r.A.sc.)
}

\section{INTRODUCTION}

RAMAN spectra of crystal powders of many acetates were recorded by Theimer and Theimer (1950) and those of single crystals of barium, sodium and magnesium acetates by Padmanabhan (1954) and zinc and lithium acetates by Ananthanarayanan (1962). Reliable assignments of the fundamental frequencies of the acetate ion have been made by Ito and Bernstein (1956), from a study of the Raman spectra of aqueous solutions, of the acetate ion together with the infra-red data on the solid metal acetates studied by early workers. The Raman spectrum of single crystal of cadmium acetate has not been reported so far. As this salt can be easily crystallised from aqueous solutions, it was felt desirable to investigate its spectrum in single crystal form.

\section{EXPERIMENTAL}

Single crystals of dimensions $2 \times 2 \times 1 \mathrm{~mm}$. were used in the investigation. With the Hilger medium quartz spectrograph and Ilford Zenith Astronomical plates, exposures of the order of two days had to be given to record intense spectra. As the crystal faces got frosted due to the heat of the arc, light was condensed on the crystal by a short focus-condensing lens. A slit width of $0.02 \mathrm{~mm}$. was used.

\section{RESUlts}

An enlarged photograph of the Raman spectrum of cadmium acetate is reproduced in Fig. 1 together with its microphotometer record. The observed freuquency shifts in wave numbers have been marked in the figure. They have also been listed in Table I. The figures given in brackets represent the relative intensities of the Raman lines estimated visually. For the sake of comparison the wave numbers observed in the spectrum of zinc acetate dihydrate by Ananthanarayanan (1962) are also included in Table I. The 
TABLE I

\begin{tabular}{|c|c|c|c|c|}
\hline \multirow{2}{*}{$\begin{array}{l}\text { Sl. } \\
\text { No. }\end{array}$} & $\begin{array}{c}\text { Cadmium } \\
\text { acetate }\end{array}$ & $\begin{array}{c}\text { Zinc } \\
\text { acetate }\end{array}$ & Free ion & \multirow{2}{*}{ Assignments } \\
\hline & Author & $\begin{array}{l}\text { Anantha- } \\
\text { narayanan }\end{array}$ & $\begin{array}{l}\text { Ito and } \\
\text { Bernstein }\end{array}$ & \\
\hline 1 & $30(2)$ & $25(5)$ & . & Lattice \\
\hline 2 & $52(3)$ & $50(f)$ & .. &, \\
\hline 3 & $62(1)$ & $67(10)$ & .. & , \\
\hline 4 & $80(1)$ & $80(12)$ & .. & $"$ \\
\hline 5 & $95(10)$ & $91(12)$ & .. & OH... \\
\hline 6 & $122(10)$ & $109(12)$ & . & , \\
\hline 7 & $145(1)$ & .. & .. & Lattice \\
\hline 8 & $155(1)$ & $158(f)$ & .. & " \\
\hline 9 & $190(0)$ & . & . & , \\
\hline 10 & $210(5)$ & $230(4)$ & . & , \\
\hline 11 & $243(1)$ & $266(8)$ & . & , \\
\hline 12 & $308(4)$ & $\begin{array}{l}310(-) \\
420(-)\end{array}$ & $\begin{array}{l}\ldots \\
\ldots\end{array}$ & $\mathrm{Cd}-\mathrm{O}_{6}$ \\
\hline 13 & $461(3)$ & $476(1)$ & $471(f)$ & $\nu_{11}\left(b_{1}\right)$ COO inplane rocking \\
\hline 14 & $496(2)$ & $509(f)$ & .. & .. \\
\hline 15 & $685(3)$ & $695(2)$ & $650 \quad(3)$ & $\nu_{\varepsilon}\left(a_{1}\right)$ COO deformation \\
\hline 16 & $951(20)$ & $\begin{array}{l}954(20) \\
1062(f) \\
1248(f) \\
1311(f)\end{array}$ & $\begin{array}{c}926(5) \\
1052(?) \\
\ldots \\
\ldots\end{array}$ & $\begin{array}{c}\nu_{4}\left(a_{1}\right) \text { C-C stretching } \\
\ldots \\
\ldots \\
. .\end{array}$ \\
\hline 17 & $1349(5)$ & $1360(4)$ & $1344(4)$ & $\nu_{2}\left(a_{1}\right) \mathrm{CH}_{3}$ deformation \\
\hline 18 & $1445(15)$ & $\begin{array}{l}1456(15) \\
2709(2) \\
2800(1) \\
2838(1)\end{array}$ & $\begin{array}{l}\cdots \\
\cdots \\
\cdots \\
\cdots\end{array}$ & $\begin{array}{c}\nu_{3}\left(a_{1}\right) \text { and } \nu_{13}\left(b_{2}\right) \\
\ldots \\
\ldots \\
\ldots\end{array}$ \\
\hline 19 & $2898(1)$ & .. & .. & .. \\
\hline 20 & $2947(15)$ & $2937(15)$ & $2935(10)$ & $\nu_{1}\left(a_{1}\right) \mathrm{C}-\mathrm{H}$ stretching \\
\hline 21 & $2997(1)$ & $2977(1)$ & $2981(3)$ & $\nu_{7}\left(b_{1}\right) \mathrm{C}-\mathrm{H}$ stretching \\
\hline 22 & $3041(1)$ & $3038(1)$ & $3010(4)$ & $u_{12}\left(b_{2}\right) \mathrm{C}-\mathrm{H}$ stretching \\
\hline 23 & $\begin{array}{l}\text { Continuum } \\
\text { up to } \\
\mathbf{3 5 6 0}\end{array}$ & Continuum & .. & Water bands \\
\hline
\end{tabular}

f. feeble. 
frequencies of the free acetate ion and their assignments as given by Ito and Bernstein (1956) are given separately in Table II.

TABLE II

Vibrational assignment of the acetate ion

\begin{tabular}{|c|c|c|c|}
\hline Species & & Description & $\begin{array}{l}\text { Observed } \\
\text { wave numbers } \\
\text { in } \mathrm{cm} .^{-1}\end{array}$ \\
\hline \multirow[t]{5}{*}{$a_{1}$} & $\nu_{1}$ & C-H stretching & 2935 \\
\hline & $v_{2}$ & $\mathrm{CH}_{3}$ deformation & 1344 \\
\hline & $\nu_{3}$ & C-O stretching & 1413 \\
\hline & $v_{4}$ & $\mathrm{C}-\mathrm{C}$ stretching & 926 \\
\hline & $\nu_{5}$ & COO deformation & 650 \\
\hline$a_{2}$ & $\nu_{6}$ & Torsion & . \\
\hline \multirow[t]{5}{*}{$b_{1}$} & $\nu_{7}$ & $\mathrm{C}-\mathrm{H}$ stretching & 3010 or 2981 \\
\hline & $\nu_{8}$ & C-O stretching & 1556 \\
\hline & $\nu_{9}$ & $\mathrm{CH}_{3}$ deformation & 1429 \\
\hline & $\nu_{10}$ & $\mathrm{CH}_{3}$ rocking & 1020 \\
\hline & $\nu_{11}$ & COO rocking (inplane) & 471 \\
\hline \multirow[t]{4}{*}{$b_{2}$} & $\nu_{12}$ & $\mathrm{C}-\mathrm{H}$ stretching & 2981 or 3010 \\
\hline & $\nu_{13}$ & $\mathrm{CH}_{3}$ deformation & 1456 \\
\hline & $\nu_{14}$ & $\mathrm{CH}_{3}$ rocking & 1052 \\
\hline & $v_{15}$ & COO rocking (out of plane) & 621 \\
\hline
\end{tabular}

\section{Discussion}

Crystallographic data.-According to Groth (1910), cadmium acetate dihydrate crystallises in the monoclinic prismatic class with $a: b: c=2 \cdot 6076$ : $1: 21473, \beta=101^{\circ} 25 \frac{1}{2}^{\prime}$ and the hydrated cadmium and zinc acetates show similar crystal forms. Complete crystal structure analysis of this salt does not seem to have been carried out so far, while that of the zinc salt has been 
reported recently by Van Niekek, Schoening and Talbot (1953). Their structural data indicate the space group of the zinc acetate dihydrate to be $\mathrm{C}_{2 h}{ }^{\circ}$ with four molecules in the unit cell and an octahedral arrangement of the oxygens of the acetate ion and those of water molecules around the metal ion. A similar structure may be expected for the cadmium salt also even though there is no crystallographic information to support this at present.

Low frequencies.-The low-frequency spectra of acetates are expected to be quite complicated by the fact that lattice vibrations, low frequency vibrations of the hydrogen bonds and the fundamental modes of the octahedral arrangements of oxygens and water molecules around the metal ions all will be crowded in this region and overlap with each other.

There is in general a close similarity in the wave number shifts of the lattice lines in the spectra of the two acetates of $\mathrm{Cd}$ and $\mathrm{Zn}$. But the distribution of their intensities is in general different. The fairly intense lines at $30,52,210 \mathrm{~cm}^{-1}$ can be attributed to rotatory types of lattice oscillations of the molecules in the unit cell. Since the crystal appears to be isomorphous with zinc acetate, we can expect six translatory and six rotatory type of lattice oscillations active in Raman effict. The two broad and intense low-frequency lines at 95 and $122 \mathrm{~cm}^{-1}$ appear to indicate the presence of $\mathrm{O}-\mathrm{H} . \ldots \mathrm{O}$ hydrogen bonding in this crystal. Gross and his co-workers (1959) have idcntified in the Raman spectra of simple substances like light and heavy ice, formic acid crystals frequencies of the hydrogen bond in the $\sim 150-300 \mathrm{~cm}^{-1}$ region. Reid (1959) has considered the stretching motions of the $\mathrm{O}-\mathrm{H}$.... O bonds as a function of the bonded distances. The theoretically calculated frequencies vary from $850 \mathrm{~cm} .^{-1}$ for $\mathrm{O}-\mathrm{H}$.... O distance of $2.43 \AA$ to about $110 \mathrm{~cm}^{-1}$ for a distance of $2 \cdot 74 \AA$. In particular, the bonded distances $2 \cdot 64-2 \cdot 74 \AA$ can be expected to give lines in the region $120-100 \mathrm{~cm}^{-1}$ It appears therefore that such bonds are present in this crystal also. In the absence of exact structure of the crystal, this conclusion cannot be confirmed. The $308 \mathrm{~cm}^{-1}$ line has been attributed to the $\mathrm{Cd}-\mathrm{O}_{6}$ fundamental vibration as such lines are expected in this region.

Internal frequencies. - The fundamental frequencies of the acetate ion are distributed under the different symmetry types as follows: $5 a_{1}+a_{8}$ $+5 b_{1}+4 b_{2}$. The torsional vibration about the $\mathrm{C}-\mathrm{C}$. bond $\nu_{\mathrm{a}}$ belonging to the $a_{2}$ type is forbidden by selection rules to appear in the vibrational spectrum. All the remaining vibrations are active in both Raman effect and infra-red absorption. A description of these fundamental modes of the acetate ion together with their frequencies observed by Ito and Bernstein 
(loc. cit.) is given in Table II. The modes corresponding to $\nu_{10}, \nu_{8}$, and $\nu_{5}$ might have escaped detection as they overlap with the mercury lines at $\lambda 2603 \cdot 20, \lambda 2639 \cdot 93$ and $\lambda 2578 \cdot 4 \AA$.

The water band extends from 3250 to $3560 \mathrm{~cm}^{-1}$ and the lowering of its stretching frequency is thus an indication of the presence of hydrogen bonding (Nakamoto, Margoshes and Rundle, 1955).

\section{SUMMARY}

The Raman spectrum of a single crystal of cadmium acetate dihydrate has been recorded for the first time using $\lambda 2537$ cxcitation. Twenty-three lines have been observed out of which ten have been attributed to the internal oscillations of the acetate ion, nine to the lattice modes, two to low-frequency hydrogen bond vibrations. A line at $308 \mathrm{~cm}^{-1}$ and the continuum $3250-3560 \mathrm{~cm}^{-1}$ have been assigned to the $\mathrm{Cd}-\mathrm{O}_{6}$ and internal vibrations of the water molecules.

\section{ACKNOWLEDGEMENTS}

The author wishes to express his sincere thanks to Professor R. S. Krishnan for his guidance and suggestions.

\section{REFERENCES}

1. Ananthanarayanan, V. _. Proc. Ind. Acad. Sci., 1962, 56 A, 188.

2. Gross, E. F. $\quad$. Hydrogen Bonding by Hadzi, Pergamon Press, 1959, p. 203.

3. Groth, P. von. $\quad$. Chemische Krystallographie, 1910, 3, 68.

4. Ito, K. and Bernstein, H. J. Canad. Jour. Chem., 1956, 34, 170.

5. Nakamoto, K., Margoshes, Jour. Am. Chem. Soc., 1955, 77, 6480.

K. M. and Rundle, R. E.

6. Padmanabhan, V. M. .. Spectroscopic and X-ray Studies on Crystals, Ph.D. Thesis, Bombay University, 1954.

7. Reid, C. ․ Jour. Chem. Phys., 1959, 30, 182.

8. Theimer, R. and Theimer, O. Mh. Chemie, 1950, 81, 314.

9. Van Niekerk, J. N., Schoen- Acta Cryst., 1953, 6, 720. ing, F. R. L. and Talbot, J. $\mathbf{H}$. 


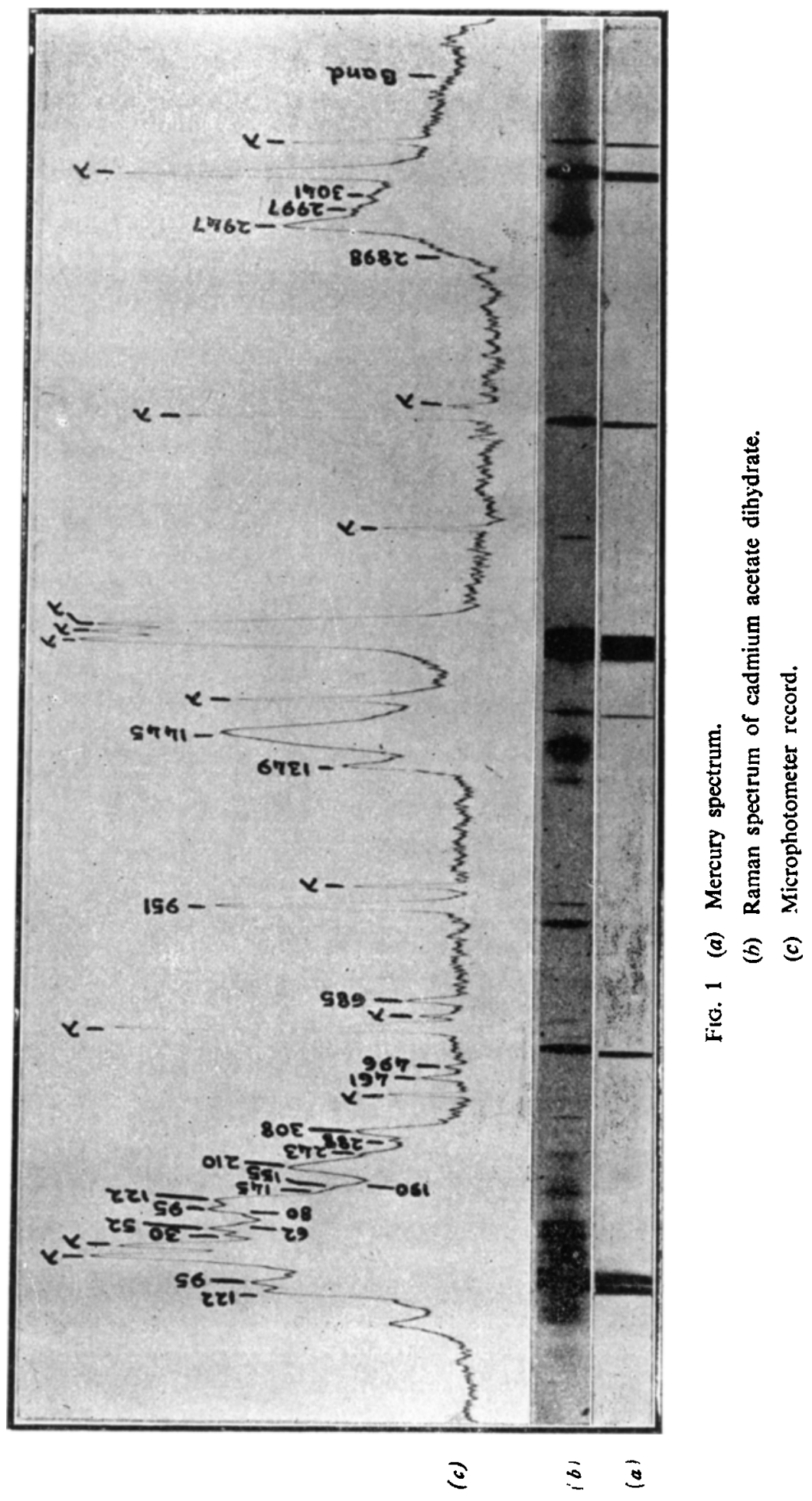

